\title{
Correlation between GDF-15 gene polymorphism and the formation of collateral circulation in acute ST-elevation myocardial infarction
}

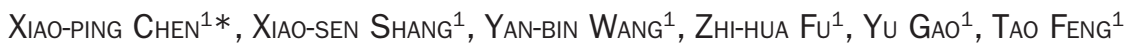

${ }^{1}$ Department of Cardiology, Taiyuan Central Hospital, Taiyuan, Shanxi, China

\section{SUMMARY}

Objective: To explore the correlation between growth differentiation factor 15 (GDF-15) -3148C/G polymorphism and the formation of collateral circulation in acute ST-elevation myocardial infarction (STEMI) in Han population of Taiyuan area.

Method: The present study included 92 STEMI patients and 56 normal controls based on coronary angiography; STEMI group was divided into collateral group and non-collateral group according to Rentrop's grading method. Polymerase chain reaction (PCR) and DNA sequencing methods were used to detect and analyze the GDF-15 -3148C/G polymorphism in all participants.

Results: There was significant difference in GDF-15 -3148C/G CC and GC distribution between STEMI group and control group $(p=0.009)$; the allele frequencies between these two groups were also significant different $(\mathrm{p}=0.016)$; and the risk genotype for STEMI was CC with increased $\mathrm{OR}=2.660$. For STEMI group, GDF-15 $-3148 \mathrm{C} / \mathrm{G}$ CC and GC distribution was also significantly different between patients with and without collateral $(\mathrm{p}=0.048)$, and CC genotype significantly promote the formation of collateral circulation. However, there were no significant differences in allele frequencies between these two subgroups of STEMI.

Conclusion: There was correlation between GDF-15-3148C/G polymorphism and the formation of collateral circulation in patients with acute STEMI.

Keywords: collateral circulation, polymorphism, genetic, growth differentiation factor 15, ST elevation myocardial infarction.

\section{INTRODUCTION}

When the coronary artery is stenotic or occluded, the formation of collateral circulation is an alternative source of blood supply to the myocardium, which may play an important role in reducing sudden cardiac death and infarct size. Therefore, the presence of coronary collaterals is crucial during acute myocardial infarction. However, significant differences exist in the degree of collateral development among different patients. ${ }^{1}$ It is very necessary to find out why some patients can develop sufficient collateral circulation while others do not.

Growth differentiation factor 15 (GDF-15) is a member of the transforming growth factor $\beta$ (TGF- $\beta$ ) superfamily, which primarily regulates multiple cellular functions as well as the growth of multiple organs and the differentiation and renovation of tissues. ${ }^{2}$ The role of GDF-15 in suppressing the progress, invasiveness and metastasis of tumors has been verified by researchers. ${ }^{3}$
Besides, it is also related to cardiovascular diseases, including cardiac hypertrophy ${ }^{4}$ and heart failure. ${ }^{5}$ Recently, GDF-15 $+157 \mathrm{~A} / \mathrm{T}$ polymorphism was found to be associated with coronary collateral formation in acute non-ST segment elevation myocardial infarction. ${ }^{6}$ Since GDF-15 -3148C/G polymorphism is closely related to left ventricular remodeling, ${ }^{7}$ whether it also plays a role in the formation of collateral vessels in the cardiovascular system remains unclear. The present study aimed to investigate the correlation between GDF-15 -3148C/G polymorphism and the formation of collateral circulation in acute ST-elevation myocardial infarction (STEMI) in the Han population of the Taiyuan area.

\section{Method}

Participants

From January 2012 to July 2016, we recruited 92 STEMI patients based on coronary angiography in Taiyuan Central 
Hospital, who were allocated into a collateral group and a non-collateral group according to Rentrop's grading method. Fifty-six (56) patients with chest pain but with normal coronary angiography were enrolled in the control group. We excluded patients with the following conditions: Non-ST-elevation myocardial infarction (NSTEMI), acute and chronic inflammatory disease, neoplastic disease, valvular disease, cardiomyopathy, angina pectoris without fixed coronary artery stenosis, $\mathrm{X}$ syndrome, coronary artery expansion, severe kidney disease (blood creatinine $>2.5 \mathrm{mg} / \mathrm{dL}$ ) and severe liver disease (ALT or AST two times higher than normal). Standardized forms were used to collect baseline data of all participants. All participants provided written informed consent.

\section{Coronary angiography and collateral vessels evaluation}

Selective coronary angiography was used according to the Judkins method. Any major coronary artery (left main coronary artery and right anterior descending coronary artery, cyclotron branch, the main diagonal branch or blunt edge branch) with pipe cavity diameter stenosis $50 \%$ and above was defined as significant coronary artery stenosis.

Using Rentrop's classification system to evaluate the collateral circulation. Level 0: no visible collateral vessel perfusion; Level 1: visible collateral blood vessels, but did not reach the contrast infusion; Level 2: visible collateral blood vessels, epicardial artery perfusion; Level 3: visible collateral blood vessels, epicardial artery was completely perfused. Rentrop's grade zero level is non-collateral group whereas Rentrop's grade $1 \sim 3$ level for collateral group.

\section{DNA extraction}

DNA was extracted from $3 \mathrm{~mL}$ of fasting venous blood in anticoagulation tube using the whole blood genomic DNA extraction kit (Beijing Bao Lai technology co, LTD).

\section{Polymerase chain reaction (PCR) and product identification}

Primers were synthesized by Shanghai biological technology co., LTD. 3148C/G site: Forward 5' - AGTGAGTCCTTGTGTCTCTTAC - 3 '; Reverse : 5 ' - GCAGGCTGGTGTAGAGTC - 3 '. Amplification system: a total of $40 \mu \mathrm{L}$ volume, $10 \times$ Buffer $4 \mu \mathrm{L}, \mathrm{MgCl}_{2} 3 \mu \mathrm{L}$, dNTP $(2.5$ $\mathrm{mM}) 4 \mu \mathrm{L}$, forward $(10 \mu \mathrm{M}) 2 \mu \mathrm{L}$, reverse $(10 \mu \mathrm{M}) 2 \mu \mathrm{L}$, Taq enzyme ( $1 \mathrm{U}) 2 \mu \mathrm{L}$, DNA $2 \mu \mathrm{L}, \mathrm{dd}_{2} \mathrm{O} 21 \mu \mathrm{L}$. Polymerase chain reaction (PCR) conditions: $94 \mathrm{C}^{\circ} 5 \mathrm{~min}$; $94^{\circ} \mathrm{C} 30 \mathrm{~s}, 55^{\circ} \mathrm{C} 30 \mathrm{~s}, 72^{\circ} \mathrm{C} 30 \mathrm{~s}$, repeat 35 cycle; $72^{\circ} \mathrm{C} 7$ min. Take $5 \mu \mathrm{L}$ PCR amplification products with load sample buffer, add sample to $1.5 \%$ agarose gel electrophoresis; the gel imaging electrophoresis products were used for analyzing.

\section{Enzyme digestion and product identification}

The PCR products were digested for 12 hours $\left(65^{\circ} \mathrm{C}\right)$. Reaction system: a total of $20 \mu \mathrm{L}$ volume, PCR products $10 \mu \mathrm{L}, 10 \times$ Buffer $2 \mu \mathrm{L}$, enzyme (BsrI enzyme) $0.5 \mu \mathrm{L}$. Take $15 \mu \mathrm{L}$ enzyme-digested products with load sample buffer, add sample to $2.5 \%$ agarose gel electrophoresis, the gel imaging electrophoresis products were used for analyzing.

\section{DNA sequence alignment}

DNAMAN and Chromas biological software were used to analyze sequencing results.

\section{Statistical methods}

SPSS 19.0 was used for statistical analysis. Measurement data were presented as mean \pm standard deviation (Mean $\pm \mathrm{SD}$ ) and compared by $t$ test; use $\mathrm{X}^{2}$ test to compare genotype distribution in compliance with Hardy Weinberg genetic balance law and inter-group gene frequencies and alleles. $\mathrm{p}$-value $<0.05$ was considered statistically significant.

\section{Results}

There was no any statistical significance between three groups in the baseline data (age, gender, smoking history, hyperlipidemia, hypertension, diabetes, family history) (all p>0.05) (Table 1).

As shown in Figure 1, both the size of GDF-15 gene PCR amplification product and CC genotype enzyme digestion product was $251 \mathrm{bp}$, while GC genotype enzyme digestion product contained three components, whose sizes were $251 \mathrm{bp}, 191 \mathrm{bp}$ and $60 \mathrm{bp}$, respectively. Both CC genotype and GC genotype were observed in all three groups.

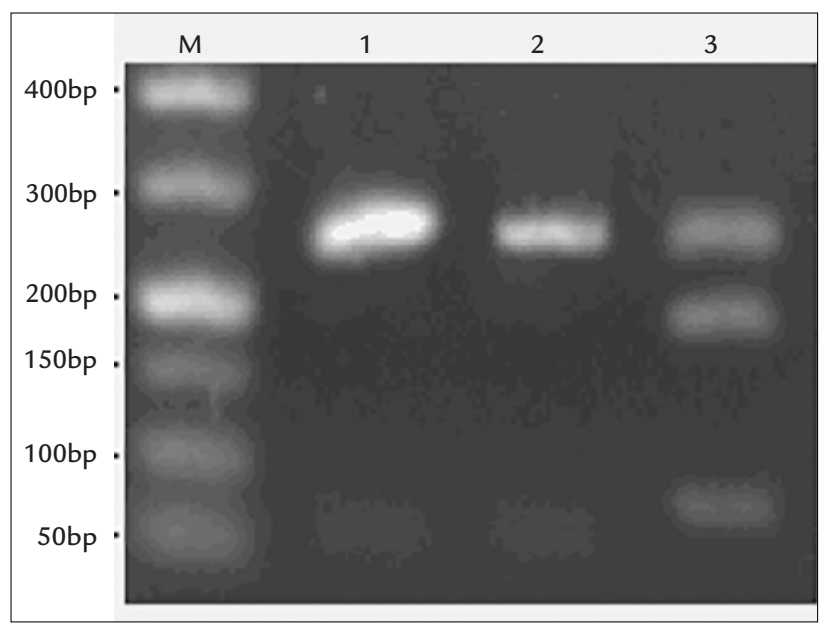

FIGURE 1 -3148C/G agarose gel electrophoresis. 1: PCR amplification products; 2: CC genotype; 3: GC genotype (M is DL500 DNA marker). 
TABLE 1 Baseline data comparison (means \pm SD or absolute numbers)

\begin{tabular}{|c|c|c|c|c|}
\hline \multirow[t]{2}{*}{ Survey index } & \multicolumn{2}{|l|}{ STEMI group $(n=92)$} & \multirow{2}{*}{$\begin{array}{l}\text { Control group } \\
(n=56)\end{array}$} & \multirow[t]{2}{*}{$\mathbf{P}$} \\
\hline & $\begin{array}{l}\text { Collateral circulation } \\
\text { group }(n=68)\end{array}$ & $\begin{array}{l}\text { Non-collateral circulation } \\
\text { group }(n=24)\end{array}$ & & \\
\hline Age (years) & $59.15 \pm 1.58$ & $59.73 \pm 1.63$ & $60.73 \pm 1.71$ & 0.453 \\
\hline \multicolumn{2}{|l|}{ Gender (n) } & & & 0.283 \\
\hline Male & 50 & 15 & 34 & \\
\hline Female & 18 & 9 & 22 & \\
\hline \multicolumn{2}{|c|}{ Smoking history $(\mathrm{n})$} & & & 0.388 \\
\hline Yes & 36 & 16 & 35 & \\
\hline No & 32 & 8 & 21 & \\
\hline \multicolumn{2}{|c|}{ Hypertension ( $\mathrm{n}$ ) } & & & 0.148 \\
\hline Yes & 38 & 18 & 29 & \\
\hline No & 30 & 6 & 27 & \\
\hline \multicolumn{2}{|c|}{ Hyperlipidemia (n) } & & & 0.361 \\
\hline Yes & 39 & 13 & 25 & \\
\hline No & 29 & 11 & 31 & \\
\hline \multicolumn{2}{|l|}{ Diabetes (n) } & & & 0.164 \\
\hline Yes & 32 & 10 & 17 & \\
\hline No & 36 & 14 & 39 & \\
\hline \multicolumn{2}{|c|}{ Family history of CHD (n) } & & & 0.363 \\
\hline Yes & 28 & 7 & 17 & \\
\hline No & 40 & 17 & 39 & \\
\hline
\end{tabular}

STEMI: ST-elevation myocardial infarction; CHD: coronary heart disease.

The results of compared sequences were the same as the enzyme digestion results. Both CC genotype and GC genotype were observed in the STEMI collateral circulation group (Figure 2A), STEMI non-collateral circulation group (Figure $2 \mathrm{~B}$ ) and normal control group (Figure $2 \mathrm{C}$ ).

The comparison of genotype frequency and allele frequency of GDF-15 -3148C/G site between the STEMI and control groups were presented in Table 2 . There was statistically significant difference in $-3148 \mathrm{C} / \mathrm{G}$ site genotype distribution $\left(\mathrm{X}^{2}=6.864, \mathrm{p}=0.009\right)$ between the two groups. Allele frequency between the two groups also had statistical significance $(p=0.016)$. The risk genotype for STEMI was CC with increased $\mathrm{OR}=2.660$.

The comparison of genotype frequency and allele frequency of GDF-15 -3148C/G locus between the collateral circulation and non-collateral circulation groups was shown in Table 3 . There was statistically significant difference in $-3148 \mathrm{C} / \mathrm{G}$ site genotype distribution $(p=0.048)$ between the two groups. However, the allele frequency $(\mathrm{p}=0.062)$ between the two groups had no statistical significance. GDF-15 -3148C/G site CC genotype might promote the formation of collateral circulation in patients with STEMI (OR=2.900).

\section{Discussion}

When the original coronary artery cannot provide enough blood flow, the collateral circulation has the potential to become the main blood supply, which can reduce sudden cardiac death and infarct size. ${ }^{8}$ As we all known, many factors may be associated with collateral development, including severity of coronary stenosis, history of myocardial infarction, use of angiotensin-converting enzyme inhibitors. ${ }^{9}$ However, none of the above reasons seems to explain an interesting phenomenon: some patients can develop sufficient collateral circulation while others do not. Therefore, we need to find new influencing factors.

GDF-15 is a member of the transforming growth factor $\beta$ (TGF- $\beta$ ) superfamily. The role of GDF-15 in cardiovascular disease has been explored by many researchers in recent years. In 2002, Brown et al. reported that serum GDF-15 protein level was an independent risk factor for women's atherosclerosis and other cardiovascular events. It was the first report that connected GDF-15 and cardiovascular disease. ${ }^{10}$ Then, the correlations of GDF-15 with cardiac hypertrophy, ${ }^{4}$ heart failure ${ }^{5}$ and coronary heart disease (CHD) ${ }^{11}$ were found gradually. A recently published article reviewed the association of 
Chen XP et AL.
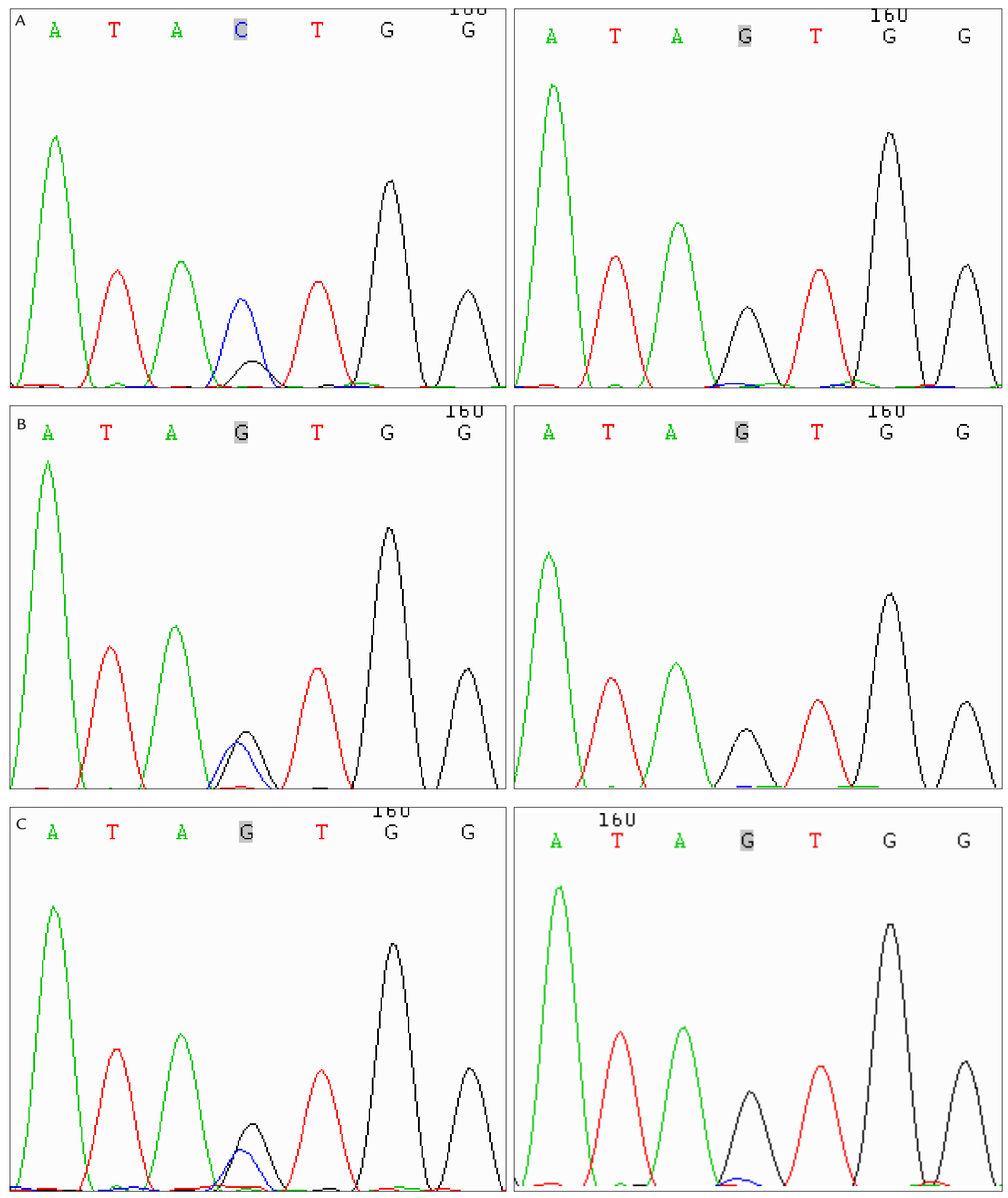

FIGURE 2 A. -3148 site genotype in STEMI collateral circulation group. B. -3148 site genotype in STEMI non-collateral circulation group. C. -3148 site genotype in normal control group (a: GC genotype; b: CC genotype).

1052

Rev Assoc Med Bras 2017; 63(12):1049-1054 
TABLE 2 Comparison of genotype frequency and allele frequency of GDF-15 -3148C/G site between the STEMI and control groups ( $\mathrm{X}^{2}$ analysis).

\begin{tabular}{llllll} 
Group & Case & Genotype & \multicolumn{3}{l}{ Allele frequency } \\
\hline & & CC & GC & C & G \\
\hline STEMI & 92 & $74(80.43 \%)$ & $18(19.57 \%)$ & $166(90.22 \%)$ & $18(9.78 \%)$ \\
Control & 56 & $34(60.71 \%)$ & $22(39.29 \%)$ & $90(80.36 \%)$ & $22(19.64 \%)$ \\
\hline$X^{2}$ value & & 6.864 & & 5.792 & \\
P-value & 0.009 & & 0.016 & \\
OR value & & 2.660 & & 2.254 & \\
$95 \mathrm{Cl}$ & $1.265-5.595$ & & $1.149-4.422$ & \\
\hline
\end{tabular}

TABLE 3 Comparison of genotype frequency and allele frequency of GDF-15 -3148C/G site between the collateral circulation and non-collateral circulation groups ( $X^{2}$ analysis).

\begin{tabular}{llllll} 
Group & Case & Genotype & \multicolumn{3}{l}{ Allele frequency } \\
\hline & & CC & GC & C & G \\
\hline Collateral circulation & 68 & $58(85.29 \%)$ & $10(14.71 \%)$ & $126(92.65 \%)$ & $10(7.35 \%)$ \\
Non-collateral circulation & 24 & $16(66.67 \%)$ & $8(33.33 \%)$ & $40(83.33 \%)$ & $8(16.67 \%)$ \\
\hline$X^{2}$ value & & 3.911 & & 3.487 & \\
P-value & & 0.048 & & 0.062 & \\
OR value & 2.900 & & $0.931-6.819$ \\
$95 \mathrm{Cl}$ & $0.983-8.556$ & & & \\
\hline
\end{tabular}

GDF-15 with the prognosis of acute coronary syndrome (ACS), finding that high plasma GDF-15 levels were associated with an increased risk of mortality and recurrent myocardial infarction in patients with ACS. ${ }^{12}$ All of the studies above indicated the vital role of GDF-15 in cardiovascular disease. Interestingly, in 2010, Sun et al. found that GDF-15 levels increased with the extent of collateral formation; ${ }^{13}$ however, the underlying mechanism was not clarified. Recently, Jing et al. observed that there was correlation between GDF-15 + 157 A/T polymorphism and the formation of collateral circulation in patients with non-ST segment elevation myocardial infarction, ${ }^{6}$ firstly connecting GDF-15 gene polymorphism with the formation of coronary collateral circulation. Apart from the $+157 \mathrm{~A} / \mathrm{T}$ site, the relation between $-3148 \mathrm{C} / \mathrm{G}$ (rs4808793) polymorphism and cardiovascular disease was also investigated. One study failed to prove an association of $-3148 \mathrm{C} / \mathrm{G}$ polymorphism with CAD or its severity in a Chinese population. ${ }^{14}$ Conversely, the other research suggested that GDF-15 -3148C/G polymorphism was closely related to left ventricular remodeling. ${ }^{7}$ Therefore, whether GDF-15 -3148C/G polymorphism also plays a role in the formation of coronary collateral vessels or not remains unclear and needs to be further clarified.

In the present study, we included 92 STEMI patients and 56 normal controls based on coronary angiography; the STEMI group was divided into a collateral group and a non-collateral group. Two genotypes of $-3148 \mathrm{C} / \mathrm{G}$ sites, CC and GC, were found both in the STEMI group and the control group, meaning that GDF-15 -3148C/G polymorphism existed in the Han population of the Taiyuan area. There was significantly difference in the distribution of these two genotypes between the STEMI group and the control group $(p=0.009)$. Allele frequencies between these two groups were also significantly different $(p=0.016)$. Moreover, CC genotype significantly increased the risk of STEMI occurrence $(\mathrm{OR}=2.660)$. At the same time, the possibility of the existence of collateral circulation in patients with STEMI carrying CC genotype could be increased by 2.9 times. However, there were no significant differences in allele frequencies between the two subgroups of STEMI; this may be due to the small sample size of this study. We need larger samples in the future researches.

Most importantly, we found that GDF-15 -3148C/G polymorphism (CC genotype) might have a correlation with STEMI occurrence and the formation of collateral circulation. Even though one study suggested that GDF15 might predict more severe coronary stenosis, which had a higher probability to develop collaterals, ${ }^{13}$ the specific mechanism of action is still unknown, further functional studies are thus needed to clarify it. Of course, our study has some limitations: first, this is a cross-sectional 
study and does not provide a mechanism explaining the results; second, the study sample might be considered small, which limits the reliability of our results; third, our results may not be applicable to the Chinese population as a whole. More longitudinal studies and functional studies in different ethnicities are needed to further investigate the pathophysiological effects of GDF-15.

\section{Conflict of interest}

The authors declare no conflict of interest.

\section{References}

1. Pohl T, Seiler C, Billinger M, Herren E, Wustmann K, Mehta H, et al. Frequency distribution of collateral flow and factors influencing collateral channel development. Functional collateral channel measurement in 450 patients with coronary artery disease. J Am Coll Cardiol. 2001; 38(7):1872-8.

2. Ago T, Sadoshima J. GDF15, a cardioprotective TGF-beta superfamily protein. Circ Res. 2006; 98(3):294-7.

3. Mimeault M, Batra SK. Divergent molecular mechanisms underlying the pleiotropic functions of macrophage inhibitory cytokine- 1 in cancer. J Cell Physiol. 2010; 224(3):626-35.

4. Dominguez-Rodriguez A, Abreu-Gonzalez P, Avanzas P. Relation of growthdifferentiation factor 15 to left ventricular remodeling in ST-segment elevation myocardial infarction. Am J Cardiol. 2011; 108(7):955-8.
5. Anand IS, Kempf T, Rector TS, Tapken H, Allhoff T, Jantzen F, et al. Serial measurement of growth-differentiation factor-15 in heart failure: relation to disease severity and prognosis in the Valsartan Heart Failure Trial. Circulation. 2010; 122(14):1387-95

6. Jing R, Liu Q, Xie Q, Qian Z. Correlation between GDF 15 gene polymorphism and the collateral circulation in acute non-ST segment elevated myocardial infarction. Int J Clin Exp Med. 2015; 8(8):14383-7.

7. Wang X, Yang X, Sun K, Chen J, Song X, Wang H, et al. The haplotype of the growth-differentiation factor 15 gene is associated with left ventricular hypertrophy in human essential hypertension. Clin Sci (Lond). 2009; 118(2):137-45.

8. Traupe T, Gloekler S, Marchi SF, Werner GS, Seiler C. Assessment of the human coronary collateral circulation. Circulation. 2010; 122(12):1210-20.

9. Altin T, Kilickap M, Tutar E, Turhan S, Atmaca Y, Gulec S, et al. The relationship of chronic angiotensin converting enzyme inhibitor use and coronary collateral vessel development. Int Heart J. 2007; 48(4):435-42

10. Brown DA, Bauskin AR, Fairlie WD, Smith MD, Liu T, Xu N, et al. Antibodybased approach to high-volume genotyping for MIC-1 polymorphism. Biotechniques. 2002; 33(1):118-20.

11. Kempf T, Sinning JM, Quint A, Bickel C, Sinning C, Wild PS, et al. Growthdifferentiation factor-15 for risk stratification in patients with stable and unstable coronary heart disease: results from the AtheroGene study. Circ Cardiovasc Genet. 2009; 2(3):286-92.

12. Zhang S, Dai D, Wang X, Zhu H, Jin H, Zhao R, et al. Growth differentiation factor- 15 predicts the prognoses of patients with acute coronary syndrome: a meta-analysis. BMC Cardiovasc Disord. 2016; 16:82.

13. Sun T, Huang Y, Phillips MI, Luo X, Zhu J, Shi H, et al. Growth differentiation factor 15 and coronary collateral formation. Clin Cardiol. 2010; 33(1):E1-5.

14. Chen Z, Xie F, Ma G, Feng Y, Qian Q, Liu N. Study of the association between growth differentiation factor 15 gene polymorphism and coronary artery disease in a Chinese population. Mol Biol Rep. 2011; 38(8):5085-91. 